\title{
Tracking the evolution of new and emerging S\&T via statement-linkages: Vision assessment in molecular machines
}

\author{
DOUGLAS K. R. RoBINSON, MARTIN RUIVENKAMP, ARIE RIP
}

Department of Science, Technology, Health and Policy Studies, University of Twente

Twente (The Netherlands)

The past 10 years has seen an explosion of interest for the area of science and technology labelled "nanotechnology." Although at an early stage, nanotechnology is providing a space for the creation of new alliances and the forging of new ties in many actor arenas, initiated based on promises and high expectations of the fruits that could be harvested from development and investment into nanotechnology. Those trying to characterise the dynamics of emerging ties and networks within this field are faced with a number of complexities which are characteristic of the nanotechnology umbrella term, which covers many technologies, various mixes of disciplines and actors, and ongoing debates about definitions of fields and terminology.

In this paper we explore an approach for capturing dynamics of emergence of a particular area of nanotechnology by investigating visions of possible futures in relation to molecular mechanical systems (molecular machines). The focus of this text is to outline an approach used to map and analyse visions in an emerging field by taking as the unit of analysis linkages made in statements in texts, and the agglomeration of linkages around certain nodes. Taking the linkage, rather than node, allows one to probe deeper into the dynamics of emergence at early stages when definitions and meanings of certain words/nodes are in flux and patterns of their use change dramatically over short periods of time.

As part of a larger project on single and macromolecular machines we explore the dynamics of visions in the field of molecular machines with the eventual aim to elucidate the shaping strength of visions within nanotechnology.

Received November 20, 2006

Address for correspondence:

DOUGLAS K. R. ROBINSON

Department of Science, Technology, Health and Policy Studies

University of Twente, The Netherlands

E-mail: d.k.r.robinson@utwente.nl

0138-9130/US \$20.00

Copyright (c) 2007 Akadémiai Kiadó, Budapest

All rights reserved 


\section{Introduction}

The past 10 years has seen an explosion of interest for the area of science and technology labelled "nanotechnology." Already at an early stage, promises have led to high expectations of the fruits that could be harvested from the development and investment into nanotechnology. Various technological fields are emerging beneath the umbrella term, some are extensions of what was already happening (cf. CMOS progressing along the ITRS roadmap towards the nanoscale) but in many cases new networks are forming based around expectations and promises of altogether new technologies made possible by manipulation at the nanoscale. Besides providing space for interaction between various technological fields the 'nanohype' offers opportunities for further development of nanotechnology through government programmes and financial investments mobilised through utopian visions and high expectations.

The far-reaching impacts of nanotechnology touted by both proponents and opponents of the emerging field calls for a need to assess possible directions for the field of nanotechnology with a focus on governance of the co-evolution of nanoscience, nanotechnology and society (RENN \& ROCO, 2006).

For effective steering a deeper understanding of the characteristics of this emerging field is needed in order to develop a robust map for an emerging situation, but also as part of the ongoing assessments which need to be evaluated based on dynamics of path emergence.

Mapping dynamics of nanotechnology is complex. First of all, the ambiguity in nanotechnology's ontology provides opportunities for relabbelling of a variety of technologies as nanotechnology. Secondly, within the field of nanotechnology terms such as nanomedicine, nanoelectronics, bionanotechnology etc. have different meanings and different usages depending on the context and actor using them. Nanotechnologies cover many industry chains, many sectors and many research disciplines which become even more complex at the nexus of convergence of these chains sectors and disciplines.

As apart of a larger programme on technology assessment (TA NanoNed) we are interested analysing indicators of emerging structures within the field of nanotechnology, and develop ways of using such knowledge to improve governance processes.

As a first step, we investigate a particularly interesting field of nanotechnology, that of molecular machines. This field has been linked to the discussions on nanotechnology since the famous lecture of Richard Feynmann (FEYNMANN, 1959) and the now infamous book of Eric Drexler Engines of Creation (DREXLER, 1986). The field of molecular machines is also an interesting case due to the very early stages of the field, the different (often separate) research communities investigating and discussing possibilities of molecular machines. 
For molecular machines, drawing boundaries around a molecular machine research community is difficult. From first round interviews with a number of researchers in the field of molecular mechanics, we see a number of camps, which need not be opposed, but originate from a different discipline with their own specific search heuristics, expectations and agendas; Biologists investigating protein machinery, chemists making interesting molecules, physicists looking at individual molecule dynamics etc. Thus there are, at the moment, a number of spheres of science which are forming molecular machine communities.

The nanohype has also provided a space for further development of molecular machines and the building of new linkages between previously disparate research communities. There is a convergence of communities with a broad notion of harnessing molecular mechanisms to do work - molecular machines.

Beyond the realms of scientific research, the nanohype has also allowed space for (enabled) other actors to enter the debate on molecular machine futures such as: Nongovernmental organisations (such as the ETC Group and Greenpeace), futurists, consumer groups and even the British Royal family (Charles the Prince of Wales ${ }^{1}$ ). Thus at very early stages of emergence there is a great diversity of actors involved in articulating hopes and fears in the expected futures related to molecular machines.

Visions and expectations of possible futures for molecular machines are interesting as they shape activities in both the research sphere and in broader societal debate. This study, which is part of a larger project on vision assessment, is carried out through the application of a tool to systematically map expectations and visions concerning molecular machines. The aim of this pilot project is to explore the robustness of this tool by using a data set taken from the reference list of a recent review article on molecular machines in the $1^{\text {st }}$ issue of Nature Nanotechnology. This core data set will be further contrasted with a smaller data set taken from the database of articles of the British popular science magazine New Scientist.

These datasets will be used to analyse linkages made in texts by various actors, who, by doing so link different actants together. By using this tool, which will be elaborated below, we wish to map the expectations and visions within the datasets, through analyses of statement linkages, and evaluate the types of visions presented.

Such mapping can reveal dynamics of emergence at early stages, before more formal ties are present. This is advantageous for steering activities, which is attractive for prospective nanotechnologies which are touted to be breakthrough science and technologies.

The aim of this paper is to present a new approach to mapping dynamics of an emerging field based on statement-linkages. We demonstrate this tool through a pilot

\footnotetext{
${ }^{1}$ The Prince of Wales published an article on nanotechnology risks and responsibility in the Independent on Sunday, a British newspaper, on $11^{\text {th }}$ July 2004.
} 
project based upon two data sets, reflective of the forms of data that will form the basis of a larger study of nanotechnologies based around vision assessment.

\section{Statement linkages as a relevant unit of analysis}

There is a rich literature of the use of words in texts to map the dynamics of science and technology. Word occurrence and co-occurrence has been used to map for instance the growth of a field, identifying research communities and taking words as actants tracking words as indicators of shaping effects within the field.

We will not review this wealth of literature here, but highlight that what all of these analyses have in common is the focus on keywords as nodes of the network and the cooccurrence of these words being the attribute of a linkage. Some of these words may become macro-actors in the sense they begin to dominate co-word maps with many linkages being made. Due to the very early stage of nanotechnology, such co-word analysis may be misleading as analysis occurs as the field is emerging, where we are still located in very early stages in the lifetime of nanotechnology. In accordance with this, the contexts in which terms are used in emerging S\&T are constantly in flux.

For example, in nanotechnology terms such as nanomedicine, nanoelectronics, bionanotechnology etc. have different meaning and different usages depending on context and actor using them. We will not go into the problems posed by the definition of nanotechnology term here, however it can be generalised that in nanotechnology new terms have fluctuating meanings depending on the context in which they are embedded. Thus, for nanotechnology (and perhaps more broadly to new and emerging S\&T) the linkage itself, made by an author in a text, becomes interesting. Thus a refocusing from co-occurrence of terms, to the linkage that joins them seems promising.

When making a statement in a text, an author may link actants ${ }^{2}$ together by making a linkage between them. We claim that one can look for specific types of linkages related to emergence of a technology and use them to characterise the emergence of the field itself. In addition, for an emerging field one can attempt to gauge the modality of the linkage, which may enable the analysis of the evolution of a specific linkage over time, i.e. if it is taken up and used by other actors. Focus on the statement-linkage allows one to get deeper into the translations that are going on in an emerging field. The actants that are involved which are defined and positioned by the linkages made by authors.

Below is an example of a statement linkage taken from an article concerning molecular machines.

\footnotetext{
${ }^{2}$ Actants are the network nodes in Actor-Network Theory (CALLON et al., 1986) where the actor-network is the sum of the translations occurring between actants at a particular time. The term actant, rather than actor is used to denote that the node may be a not only be a person or institution etc. but can also be an artifact that shapes the network through translation.
} 
"Biological molecular motors are capable of performing specific tasks in response to specific external energy sources in a highly sophisticated fashion and thus may soon be utilized in nanoscopic devices." (HOLLAND et al., 2003: p. 2015)

Here biological molecular motors are connected with (near) future nanoscopic devices through a statement linkage made by Holland et al. The statement was made in a peer-reviewed journal for the study of macromolecules and positioned naturally occurring protein molecular motors as a component of a synthetic device.

A focus on such vision-based linkages, statements about the future, is useful for gauging activities during very early stages of an emerging field of science and technology where decisions and actions are based on promises and expectations against the backdrop of institutional settings and actor networks. For S\&T under the umbrella term of nanotechnology, many actors who would traditionally be involved in the field later on in the innovation chain are becoming involved at the outset, articulating there own expectations and agendas, and shaping the directions for activities which contribute to the emergence of the new technology field.

Thus, the monitoring of such linkages seems attractive as it may allow the systematic exploration of a data set, pulling out indicators of emerging alignment based on visions, expectations and agendas. This is important for very early stages of a nascent technology field, as visions and expectations guide activities (to varying degrees) prior to agenda setting and concrete activities.

\section{Visions as guiding forces during early stages of emergence}

Due to the immaturity of many nanotechnology fields, expectations and promises play a dominant role by mobilising resources and action in the shaping of an emerging S\&T. Over the last 10 years, the sociology of expectations has argued about the structuring of action by expectations, especially at early stages where the situation is fluid and there are opportunities to create new ties and positions (VAN LENTE, 1993; VAN LENTE \& RIP, 1998; BROWN \& MiCHAEL, 2003; VAN MERKERK \& ROBINSON, 2006; BORUP et al., 2006). In nanotechnology, one can argue that expectations are particularly important, since resources are being mobilised into investing in nanotechnology based on promises rather than concrete products or proofs of principle, and in so doing structuring and guiding action.

In addition to expectations, there is another type of promise, which can be linked to visions. Visions can take the form of images or texts, and stretch from a near term vision (close to expectations) to science fiction. Vision linkages in text may have varying degrees of facticity in various communities, but in the emerging field of nanotechnology, even the science-fiction visions have strength, by shaping public debate and activities even though the vision is accepted as a fantasy. 
A recent stream of activities under the heading of Vision Assessment (GRIN \& GRUNWALD, 2000; GRUNWALD, 2004) seeks to explore the role of visions in the coevolution of science, technology and society. The idea behind Vision Assessment is not to create new visions that may shape socio-technical systems, but "that visions exist already in most societal sectors, that these visions tend to reproduce the ways in which these sectors have developed hitherto, and that a critical discussion of these visions is a prerequisite for changing the course of development." (DECKER, et al., 2000: p. 1)

In this way it is sought to contribute to a reflexive development of emerging technologies through a constructive assessment, not only of actual technological practices, but also of future visions and the underlying presuppositions of these technological practices as well.

As part of the larger project on the emergence of nanotechnologies ${ }^{3}$ we are interested in emerging alignment and networks within the field of nanotechnology for particular streams of development (such as drug delivery, nanoelectronics etc.). The analysis of the population of nodes and linkages, its configuration and the modalities of the linkages can give indicators into path dynamics (RoBINSON, 2006a) such as a dominant vision aligning actors, or path creation (GARUD \& KARNØE, 2001) in a community.

Monitoring such indicators is essential for enabling real-time evaluation and steering of an evolving and emerging field of technology, a key component of the Technology Assessment programme.

\section{Scope of this pilot study}

This paper will focus on the exploration of the statement-linkage approach in mapping new and emerging S\&T. The first round approach, which is described in the paper, is applied to the field of molecular machines, as part of a project which aims to map the dynamics of the emerging field of controlled molecular motion. In line with this special issue, we apply the tool to the mapping the field of molecular machines as described in a recent review article published in the first issue of Nature Nanotechnology. Furthermore, statement linkages are tracked in several articles published in the popular science magazine New Scientist.

\section{Data}

The field of molecular machines is discussed in many different settings and in many different arenas. In this article two specific fora have been selected in which statement

\footnotetext{
${ }^{3}$ See the technology assessment programme within the Dutch nano consortium, NanoNed led by Arie Rip, University of Twente, The Netherlands. http://www.nanoned.nl/ta
} 
linkages have been tracked. Firstly, the reference list of a review article published in the recent first issue of Nature Nanotechnology have been examined. Secondly, several search items were used to demarcate the field of molecular machines in the popular science magazine New Scientist. The interest in including this complimentary data set is to ascertain if there is a different modality spread of the linkages made in these fora, but also to see the types of nodes and linkages made with a view to our claim that this tool can handle heterogeneous data sets in a systematic way.

\section{Nature Nanotechnology}

In early October 2006 a new supplement to the journal Nature was launched with a specific focus on nanotechnology. Nature Nanotechnology can be seen as a landmark, as a recognised forum for research in nanotechnology originating from any natural science discipline.

In the first issue of Nature Nanotechnology ( $6^{\text {th }}$ October 2006) a review article covering the last 5-6 years of investigations into molecular machines was published. Of the two authors (who are supramolecular chemists) Ben Feringa of Groningen is a recognised world leader in artificial molecular motors. Wesley Browne is a Post Doctoral Student in the Feringa group.

For this pilot study we take the reference list of this review article to map the visions of the molecular machines community bounded by Ben Feringa through his review article. There is a natural bias, they are both chemists, but since this is a review article in the first Nature Nanotechnology, they highlight relevant work and make a claim on which visions they deem relevant and which they do not.

\section{New Scientist}

Since the broader project will also investigate linkages outside peer-reviewed fora, which may inhibit some of the more visionary types of linkages, we also apply our tool on another forum for the discussion of scientific endeavour in molecular machines - the popular science magazine New Scientist. New Scientist is a weekly publication for the interested lay audience and students of science. It is a forum for many different actors mainly through journalists but also authored by other actors from NGOs (such a Greenpeace) to supramolecular chemists (such as Vincenzo Balzani editor of the book Molecular Machines - BALZANI et al. (2003)). There is no peer review, but a need for newness and by the very nature of the journal, a need for less conservative claims in order to attract the interest of the reader. Nonetheless, scientists who publish here are taken to be spokespersons for the field.

To be able to demarcate the field of molecular machines among the many different topics discussed in the New Scientist, it has first of all been chosen to search for articles 
in New Scientist Tech, a web service which provides all articles from the New Scientist since 1989. The search terms where based on key words chosen relating to the number of definitions of molecular machine and nanomachine taken from literature and from interviews.

Below are two examples of the types of definitions of molecular machine available in the literature.

"A machine is defined as "an assembly of parts that transmit and modify forces, motion, and energy one to another in a predetermined manner". When the word "parts" is replaced by "molecules", a machine turns into a molecular or supramolecular machine. Therefore, a molecular machine is defined as an assembly of a distinct number of molecular components designed to perform machine-like movements in response to an appropriate external stimulus. In addition, a molecular machine has features characteristic of the molecules. In biological systems, there are many molecular and/or supramolecular machines, such as enzymes, antibodies, and viruses." (HARADA, 2001: p. 456)

"At the heart of every machine is its motor. The Oxford Dictionary of English defines a motor as "a thing that imparts motion"; work as "the operation of a force in producing movement or other physical change"; and motion as "the condition of a body, when at each successive point in time it occupies a different position or orientation in space". Perhaps, a more utilitarian definition of a motor is a device that converts fuel, be it chemical, thermal or light, into kinetic energy in a controlled manner - that is, it makes things move." (BROWNE \& FERINGA, 2006: p. 26)

Thus we take a molecular machine to be an assembly of molecules which converts chemical, thermal or light energy into kinetic energy in a controlled manner. We also took a similar definition for nanomachine where "assemblies of molecules" was replaced with "assemblies of nanoscale components". This led to a number of search terms which where fed into the search engine of the New Scientist archive which stretched from 1989 to the present (October $1^{\text {st }}$ 2006). This provided to 97 articles.

A list of search terms for the New Scientist archive can be found in Appendix 1.

We use this tightly focussed exploration as a basis for further refinement of the approach for the mapping of a more broad molecular machine data set, and later for other nanotechnology fields, which is work in progress conducted by the lead author. For this project, exploration of trajectories of nanotechnology, or more broadly nanotechnology paths (ROBINSON, 2005; ROBINSON, 2006a) are important. A deeper understanding in the dynamics which lead to certain paths becoming dominant rather than others is a key asset to foresight and strategy articulation exercises (RIP et al., 1995; RoBINSON \& PROPP, 2006, RoBInsOn, 2006b).

The following section describes the method used to understand the evolution of an emerging field, as it is defined through linkages made in texts, and their modalities. The objective is to investigate how expectations of the future evolve (or fail to evolve) into 
agenda setting activities and concrete action within a socio-technical network. Mapping of expectations and shared agendas allows one to explore emerging patterns leading to alignment within the field and possible irreversibilities, which can set in.

\section{Methodology}

The tool has been designed and used in this pilot study to get a handle on the dynamics and evolution of emergence in the field of molecular machines. The focal data point that we take is the statement-linkage, that is a connection made between two nodes/keywords by an author of a text. The node can either be an actor or technology component/characteristic. The linkages we are interested in pertain to visions and expectations.

\section{Linkages and modalities}

As mentioned previously we take linkages which describe claims about future activities within the field of molecular machines. We have drawn on the literature of sociology of expectations (VAN LENTE, 1993; VAN LENTE \& RIP, 1998; BROWN \& Michael, 2003; VAN MERKerK \& Robinson, 2006; Borup et al., 2006) and Vision Assessment (GRIN \& GRUNWALD, 2000; GRUNWALD, 2004) to develop a classification of the modality of linkage from proof of concept through to science fiction.

Science Fictions indicate long-term fictional ideas, which are accepted as fantasy without demands of feasibility. An example of a Science Fiction linkage could be: "The dark side of nanotechnology is "grey goo" - the nightmare possibility that "nanorobots" could be programmed to gobble up their surroundings and turn everything on Earth into more nano-robots". (PARK, 2003)

Visionary Linkages indicate long-term technological possibilities, which are accepted as reality-based fantasies, which could claim feasibility. An example of a Visionary Linkage could be: "The behaviour of devices at these scales could eventually mean fundamental changes in the way we build things, forcing us to abandon old ideas". (Сно, 2001)

Guiding Visions denote more technical and plannable technological futures (GRIN \& GRUNWALD, 2000) such as their paperless office. An example from the world of molecular machines would be "Powering nanoscale machinery by nanosized motors that move by in situ conversion of stored chemical energy is one of the most interesting challenges facing nanotechnology." (KLINE et al., 2005: p. 744)

The difference between Guiding Visions and Visionary Linkages is that Guiding Visions imply action, although no actor is positioned to undertake it (a more general statement). 
An Expectation Linkage, of a constituent of the future molecular machine world. An example of an expectation linkage could be: "We expect that the successful formation of fully functional surface-mounted rotors will enable investigation of the concerted action of a large ensemble of unidirectional molecular motors, and that this system might be a first step towards the construction of more elaborate and functional nanosized mechanical devices." (VAN DELDEN et al., 2005: p. 1340)

A shared Agenda (goal) of what future action should or will be taken. An example of an agenda statement could be: "This paper is the first step towards our goal of creating artificial complex systems composed of large numbers of components that move autonomously and that self assemble." (ISMAGILOV et al., 2002: p. 654)

Proof: Technological developments that have been demonstrated and are accepted as fact or reality. An example of a proof-linkage could be: "Nature already provides us with a wide range of biological nanomotors". (HESs et al., 2004: p. 2111)

These six types of linkage can be tabulated as statement linkage modalities:

\begin{tabular}{|lll|}
\hline Statement linkage & Description & $\begin{array}{l}\text { Action } \\
\text { implied }\end{array}$ \\
\hline modality & & No \\
Visience Fiction & It may happen (accepted as fantasy) & No \\
Guiding Vision & It may happen (accepted as reality based fantasy) & Yes \\
Expectation Linkage & It may happen & Yes \\
Agendas (goals) & It will happen & Yes \\
Proof (Proven and/or demonstrated) & We are gonna make it happen & Yes \\
\hline
\end{tabular}

A database was constructed of linkages made by authors in the data set described. The first step entailed the identification of a statement based on whether the sentence referred directly to the field of molecular/nanomachines. Once we identified such a statement, we determined whether the statement housed one or more of the six types of linkage outlined above.

Once a relevant linkage was found, this was entered along with details of the author (name, institution and country), the title of the article, the journal name and the page number. Each node was entered along with the linkage modality and the whole statement.

\section{Visualising the statement-linkages}

In this pilot we will use a simple ring structure representing the six different modalities mentioned above. Each modality map will map the nodes and linkages related to a specific node. In Figure 1 you can see an example. For each node there is a line. The line may stretch across a number of rings, which shows that there is a mix of modalities for this linkage. Along this line are circles, the larger the circle, the more linkages there are. This visual allows you to get a glimpse at what is in the database 
related to a particular node. In the fictitious example in Figure 1, we can see two type of linkages mapped. Molecular-rotor to ATP-synthase and Molecular-rotor to nanodevice.

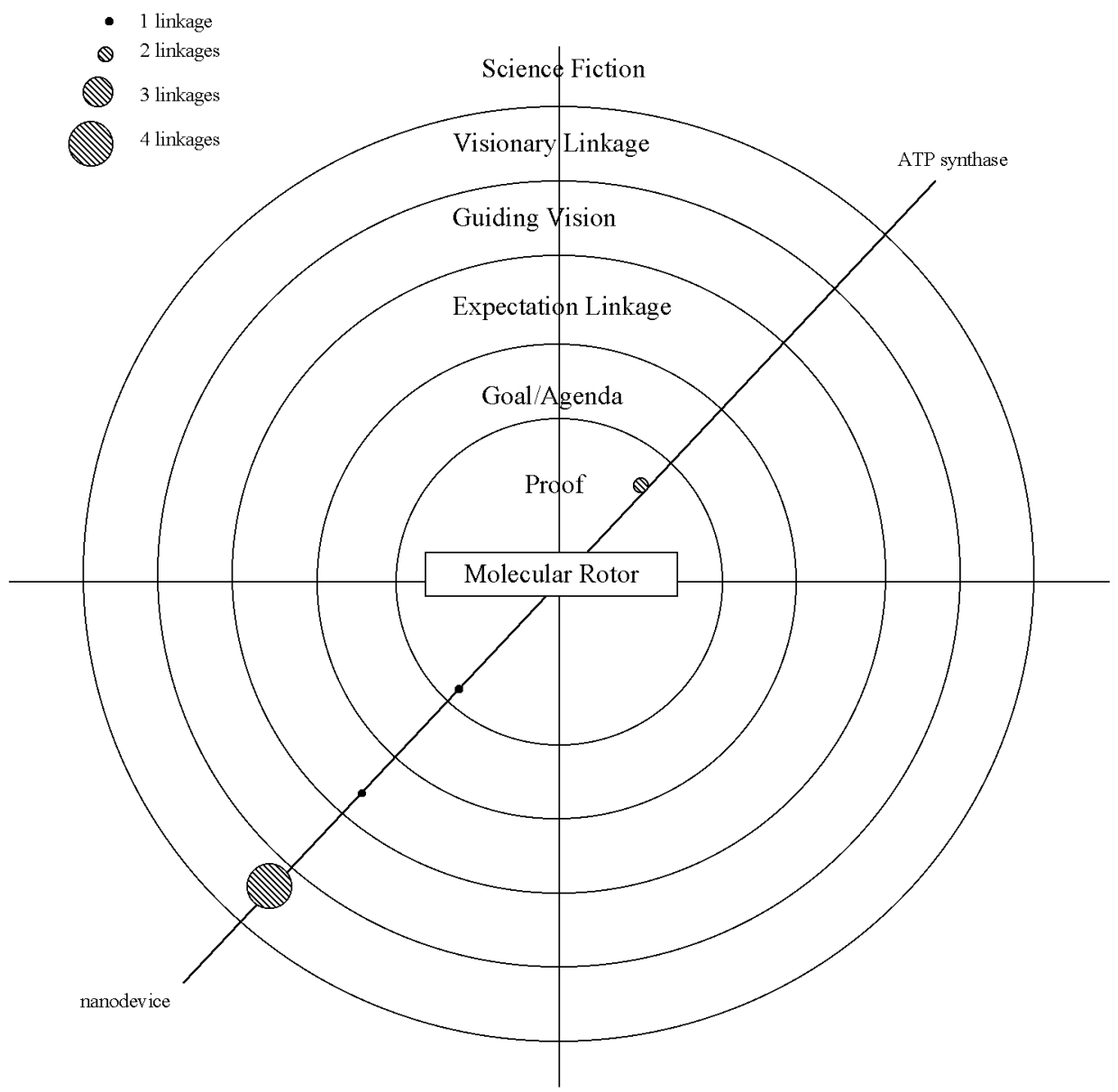

Figure 1. Modality-map showing linkages to molecular machines

For the ATP-synthase linkage we see that 2 linkages with the Proof modality. For the nanodevice linkages, we see 4 linkages with a Visionary Linkage modality, 1 with an Expectation Linkage modality and 1 with a Proof modality.

Full modality maps would show all the linkages made to a particular node. 
D. K. R. RoBINSON et al.: The evolution of new and emerging S\&T

\section{Illustrative case - Mapping vision linkages in Molecular Machines}

Richard P. Feynmann speech There is Plenty of Room at the Bottom is often referred to as the first talk on nanotechnology. In this famous address to the Meeting of the American Society of Physics in 1959, the Nobel Laureate in Physics not only considered the possibility of direct manipulation of individual atoms, but laid down the challenge to construct mechanical machines at the nano (molecular) scale as well.

"What are the possibilities of constructing molecular-scale mechanical machines?... An internal combustion engine of molecular size is impossible. Other chemical reactions, liberating energy when cold, can be used instead.... Lubrication might not be necessary; bearings could run dry; they would not run hot because heat escapes from such a small device very rapidly...”. (FEYNMANN, 1959)

The notion of molecular machines was further brought under attention by Eric K. Drexler in 1986. In Engines of Creation, Drexler describes molecular assemblers as devices capable of building products from the atom up, thus with absolute precision and without pollution. However, according to DREXLER (1986), to be able to do so, these assemblers need to be able to reproduce themselves as well, something that could happen at considerably high frequency. Assuming that the first assembler could make a copy in one thousand seconds, "the two replicators then build two more in the next thousand seconds, the four build another four, and the eight build another eight. At the end of ten hours, there are not thirty-six new replicators, but over 68 billion. In less than a day, they would weigh a ton; in less than two days, they would outweigh the Earth." (DREXLER, 1986)

This idea led to the apocalyptic scenario of the 'Grey Goo', in which the process of self-replication gets out of control and the assemblers 'eat up' all life forms on earth. The 'Grey Goo' scenario was fiercely attacked by 1996 Nobel Price winner in Chemistry Richard E. Smalley, who expressed his objections against molecular assemblers through what he called the 'fat fingers' and the 'sticky fingers' problems (SMALLEY, 2001)

While the possibilities of assemblers were debated on a scientific and public level, the discovery of a family of moving proteins labelled as biological molecular machines attracted a lot of attention from, biologists, chemists and physicists (VALLEE \& HOOK, 2003; SCHLIWA \& WOEHLKE, 2003). It was argued that "these proteins [could] perform directed or programmed motions, similar to many tools and machines used in our daily life" (KINBARA \& AIIDA, 2005; p. 1377). The integration of biomolecular motors into synthetic environments has been described as one of the three possible ways to construct machines able to perform work at the nanoscale. Other "paths taken in the quest for nanoscale generation of mechanical work [are] the bottom-up design of molecular motors by chemical synthesis, [and] the top-down fabrication of miniaturized electric motors by lithography". (HESS \& BACHAND, 2005) 
In the last two decades the first biomolecular machines have been controlled to perform specific tasks, and machinery has artificially been built at the nanoscale. Nowadays the progress in the construction of molecular machines is being categorized in generations of molecular machines. For example the first generation of light driven molecular motors were characterized by their ability to perform unidirectional rotary motion upon energy uptake for which molecular chirality turned out to be an essential feature (KoumARA, et al., 2002). "Further important structural features in this first generation light-driven molecular motor are the identical nature of the upper and lower parts of the tetrahydrobiphenanthrylidene and the all-carbon framework of the molecule" (KOUMARA, et al., 2002). In second generation light driven molecular motors, the structure of the stator-parts and the rotor-parts are different, "enabling additional components to be attached to either the top or the bottom half and surface attachment of the stator". (BROWNE \& FERINGA, 2006)

For this study, we are interested in the visions of the present and future generations of development of molecular machines. The modality of the visions can tell us about the degree of acceptance of specific characteristics a future molecular machine generation may hold.

In this pilot project we explore this by taking two data sets, the core set being taken from the reference list of BROWNE \& FERINGA (2006) as a representative review of the scientific exploration and development of synthetic, natural and hybrid molecular machines. The second data set represents the scientific press, where broader debate without peer review is undertaken, thus we have selected articles from the archive of the New Scientist magazine. The latter data set could give insight into the uptake of the notion of nanomachine and the linkages made to these bolstered by the nano-hype in recent years societal debate ${ }^{4}$ on the societal impacts of nanotechnology.

\section{Results}

A total of 486 statement-linkages where obtained with the Browne \& Feringa data set and 129 statement-linkages with the New Scientist data set. The diversity of phrasing within the dataset meant that some grouping of nodes was necessary resulting in the list of nodes given in Appendix 2.

One immediate comparison of the types of linkages in both data sets (see charts below) shows a weighting more to Proof modalities for the Browne and Feringa data, which comprised mostly of peer-reviewed articles. The New Scientist data set shows a clear weighting to more visionary modalities such as Guiding Visions, Visionary Linkages and Science-Fiction linkages.

\footnotetext{
${ }^{4}$ Perhaps phrasing it as "debate on behalf of society" would be a more appropriate term to use.
} 
Of particular note was the amount of linkages to three nodes molecular machines, molecular motors and nanomachines. We chose to focus the analysis on the linkages to these three nodes due to the limited dataset meaning we should focus.
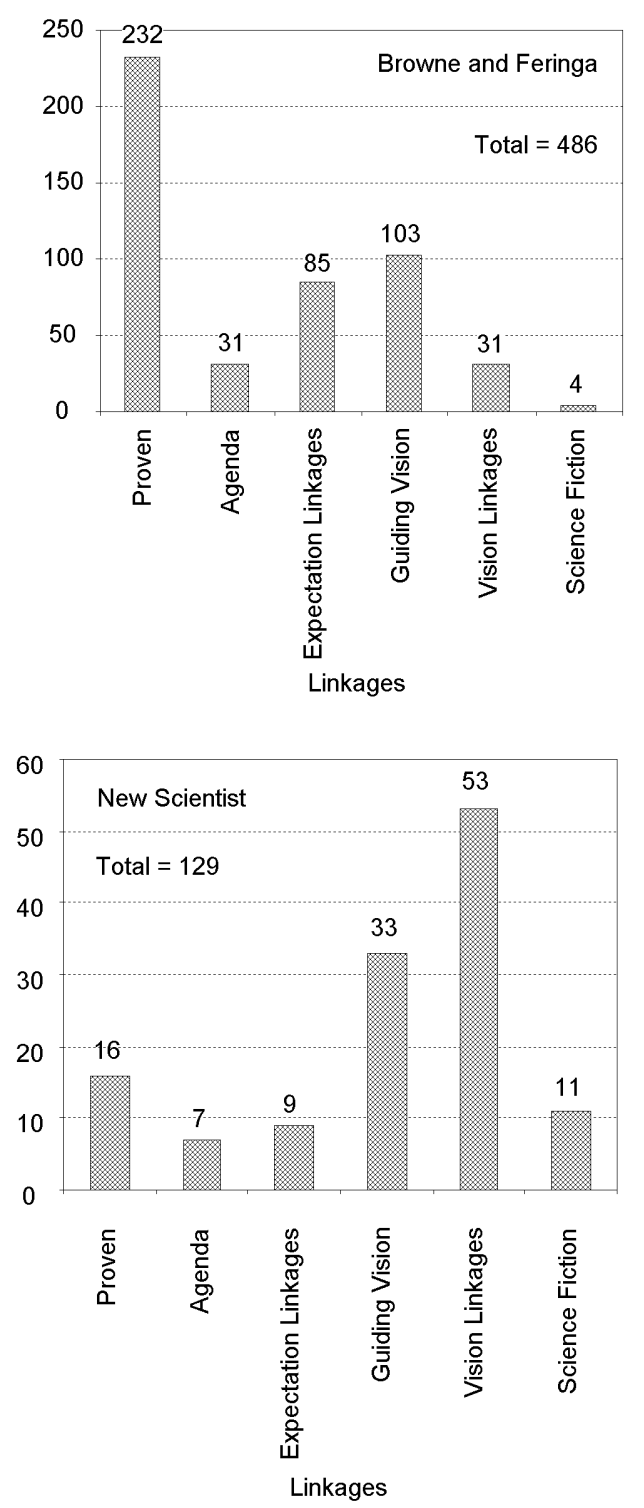

Figure 2. Linkage modality distribution in both data sets 
Figure 3 shows the modality map for nanomachines. Over the 111 reference articles in Browne and Feringa the linkages made where in the main guiding visions for the second and third generation of nanomachines. We see in the map that components of nanomachines prevail (molecular shuttles, molecular motors, DNA, nanowheels etc.) and desired functionalities (light powered, catalytic reactions). There are few linkages to devices or applications.

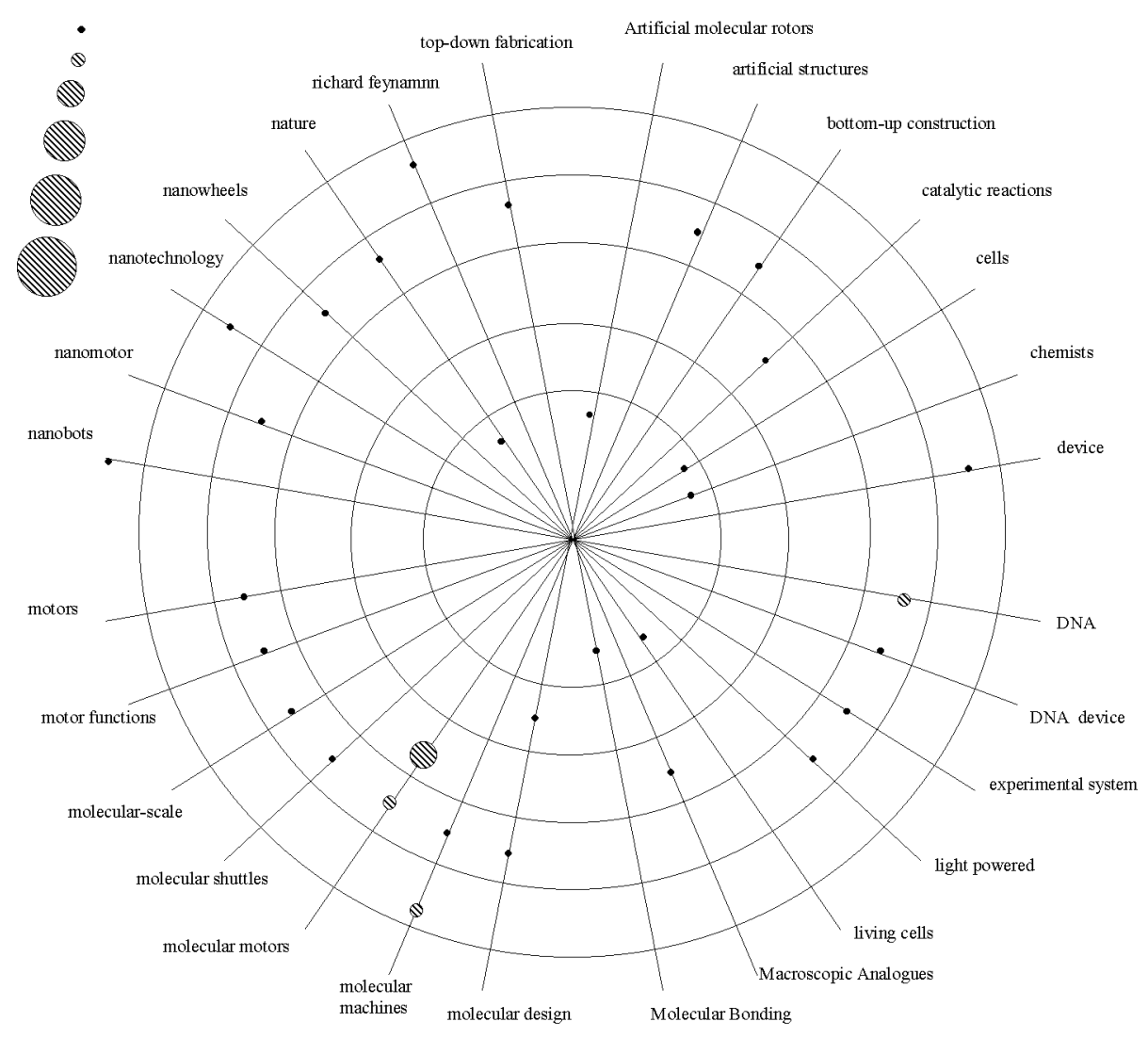

Figure 3. Modality-map for nanomachines (BROWNE \& FERINGA, 2006) 
D. K. R. RoBINSON et al.: The evolution of new and emerging S\&T

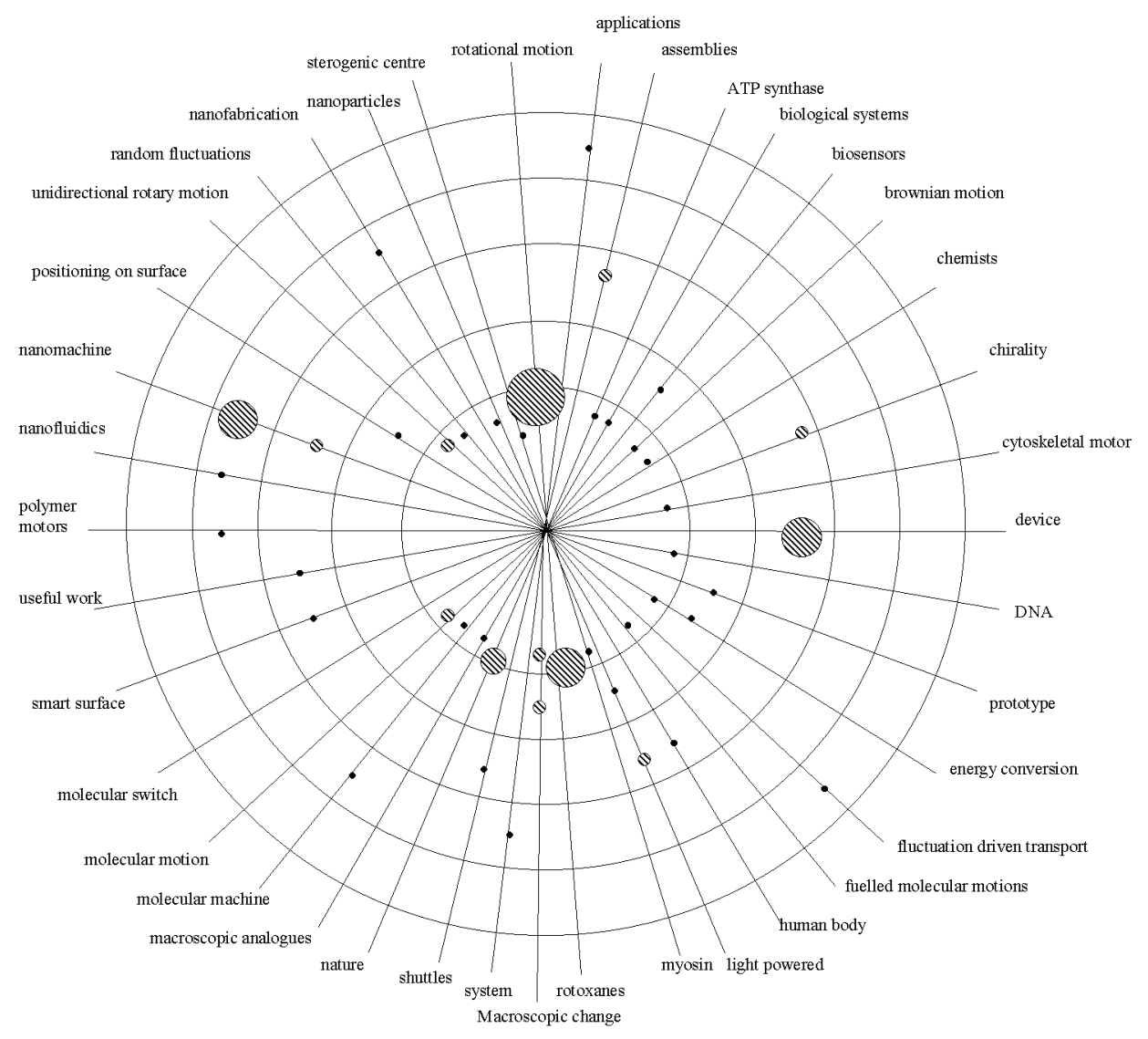

Figure 4. Modality-map for molecular motors (BROWNE \& FERINGA, 2006)

Figure 4 shows the modality map for molecular motors. Molecular motors differ from molecular machines in that they are a component, and in some case may be a single molecule).

Here we see a greater spread of linkages made than with nanomachines. Many links to desired functions (rotational motion, unidirectional motion, light powered) and more focus on devices (device, smart surface, nanomachine, molecular switch, biosensors etc.). The modality of linkages is much more centralised with proof and guiding vision dominating. We see a number of linkages being stated a number of times pertaining to the dominant investigations into molecular machines (rotoxanes and rotors) and visions of application (device, nanomachine). 


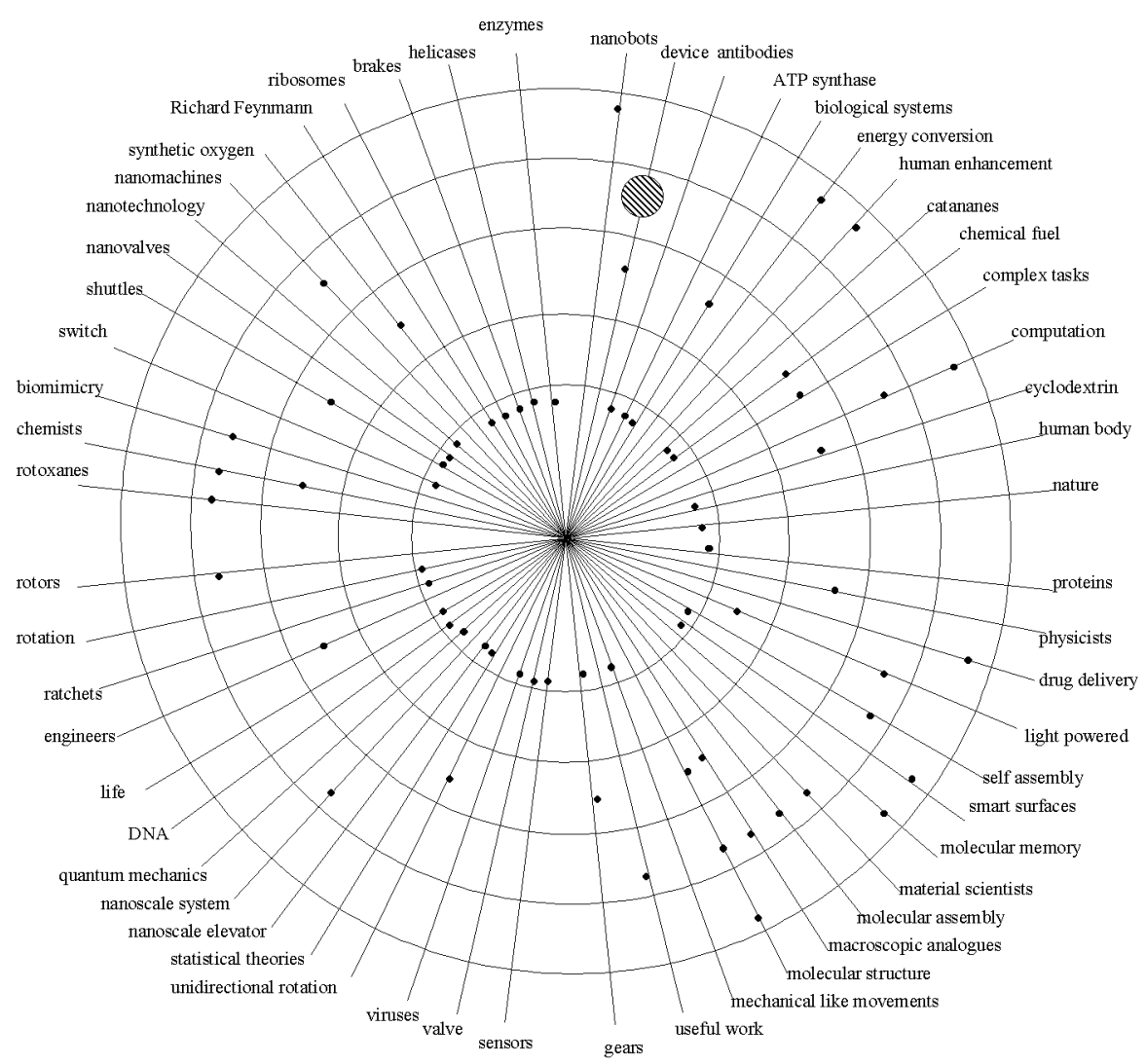

Figure 5. Modality-map for molecular machines (BROWNE \& FERINGA, 2006)

Figure 5 shows the modality map for molecular machines. There where 56 types of linkage to molecular machines, with a modality spread in the main between Proof and Guiding Vision. Within the Guiding Vision and Visionary Linkage rings one can see a dominance of linkages to applications (computation, device, antibodies, energy conversion, human enhancement, drug delivery). Actor linkages are more prevalent here (chemists, physicists, engineers, material scientists).

\section{New Scientist 1989-2006}

The number of linkages made in the articles was dramatically less than in the previous dataset. This is due to the size of the texts (approximately 1-2 pages). Figure 6 
shows the modality maps of nanomachines, molecular motors and molecular machines respectively.

In all three maps one can see a more diverse spread of linkages, dipping closer into the Science Fiction and Visionary Linkage rings. Desired functionalities do not occur, and the focus is more on applications (nanowalkers, nanomachines, grey goo) and actors (chemists. engineers, nanotechnologists).

\section{Discussion}

From the data we see a large diversity in the types of linkages made. In addition, there are few obviously dominating linkages. In Figures 3 and 5 for example, there is a dominance of single linkages whereas in Figure 4 we see the beginnings of the restating of linkages.

From the database we can observe that there are distinct generations in the perceived futures of molecular machines. $1^{\text {st }}$ generation (the present) in chemistry creation of artificial motors, rotors and walkers in solution and statistical analysis of their movements is the going concern. Biologists in the $1^{\text {st }}$ generation are attempting to understand the mechanics of natural macromolecular machines such as ATP-synthase and other protein based molecular machines.

The $2^{\text {nd }}$ generation is the positioning of molecular machines onto surface to allow useful work to be done. $1^{\text {st }}$ generation artificial molecular machines where in solution and thus floating aimlessly and not transferring their kinetic energy. The $2^{\text {nd }}$ generation is perceived to be a point where different communities can actively cooperate. Biologists working with chemists and material scientists to position natural motors into a synthetic environment.

The $3^{\text {rd }}$ generation is envisioned to see the first devices with functionalised surfaces of molecular machines. It also sees the construction of larger artificial assemblies of molecular machines into the perceived nanomachines and nanodevices.

These generations are reflected in the modality of visions. However, since the linkages where mostly taken from the chemistry community (in the case of BROWNE \& FERINGA, 2006), a further investigation into other community's visions is in order, to test the robustness and/or further define the generations of molecular machines and the perceived time frame.

The modality maps allow us to see the visions articulated by the produces of scientific and technical knowledge in the field of molecular machines, and allows us to tap into this and see the visions that guide the field.

The next step beyond this pilot study, is to undertake a study over time, to understand the dynamics of development and the to investigate the evolution of vision 
D. K. R. RoBINSON et al.: The evolution of new and emerging S\&T

linkages. This would be interesting to monitor in a number of communities, especially with those deemed to be converging. ${ }^{5}$

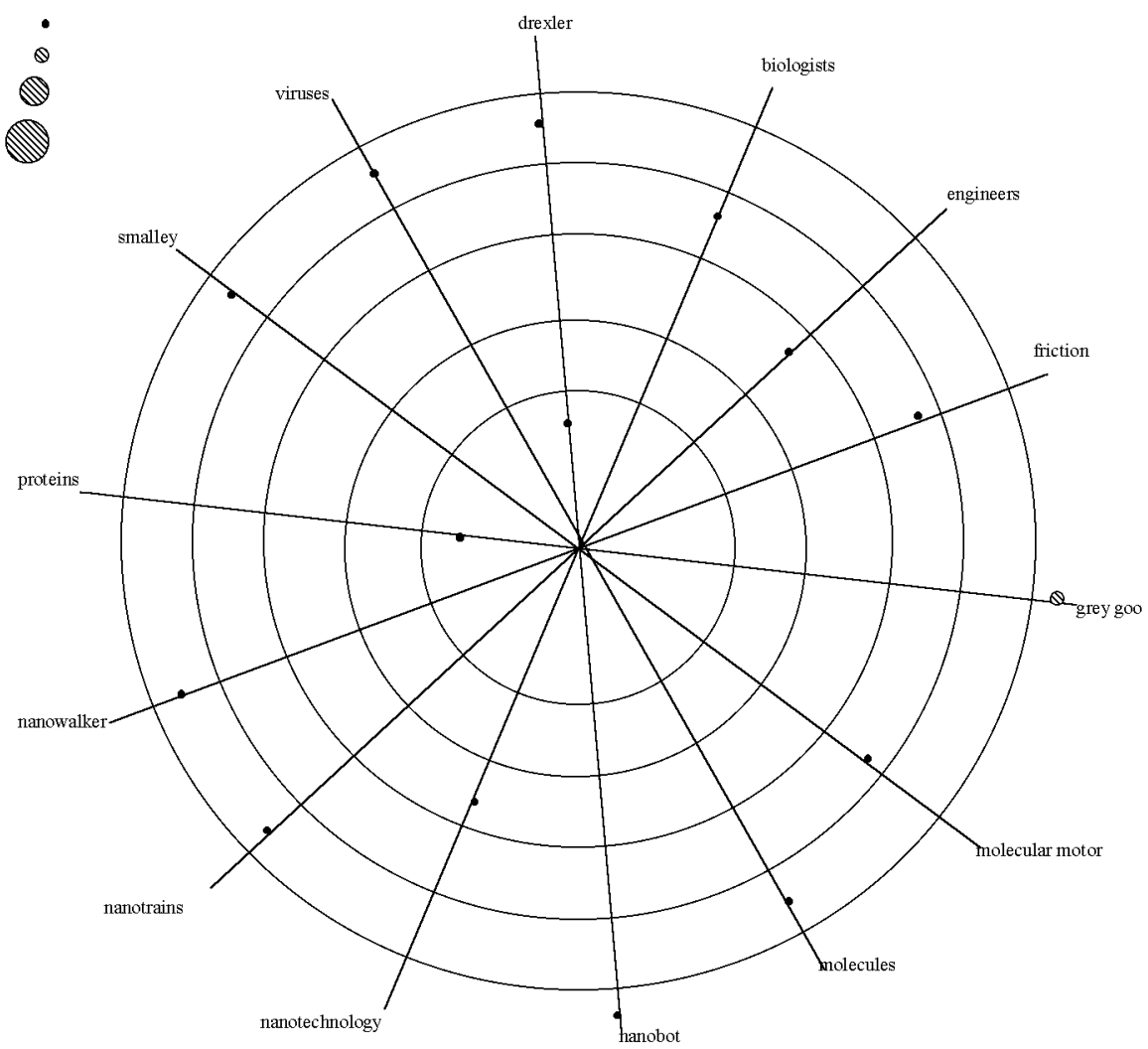

Figure 6a. Modality-maps for (a) nanomachines (New Scientist)

${ }^{5}$ There are indications from our data set that the chemists and biologists are beginning to create the same linkages, and initiate collaboration on hybrid molecular machines. 
D. K. R. RoBINSON et al.: The evolution of new and emerging S\&T

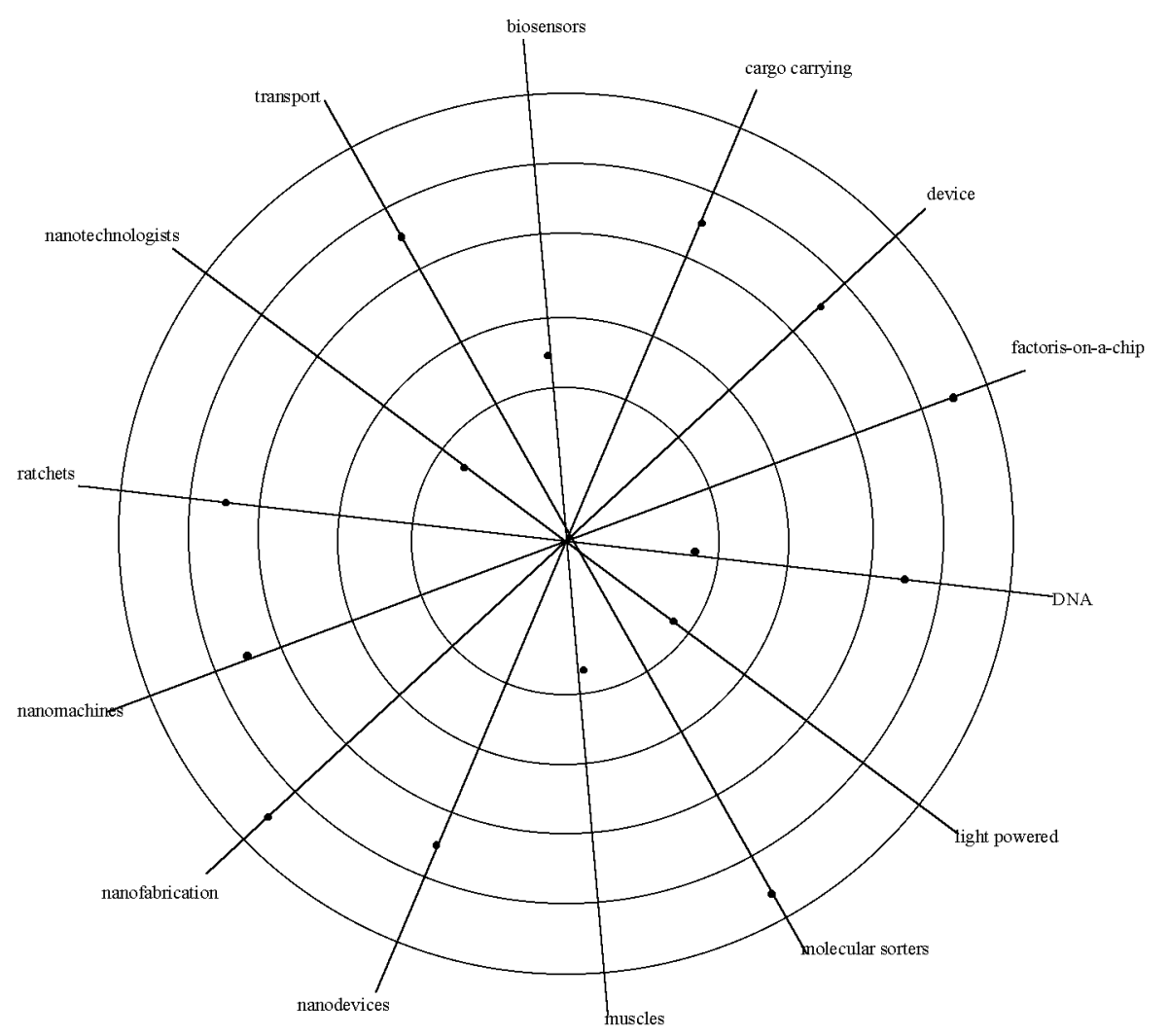

Figure 6b. Modality-maps for (b) molecular motors (New Scientist) 


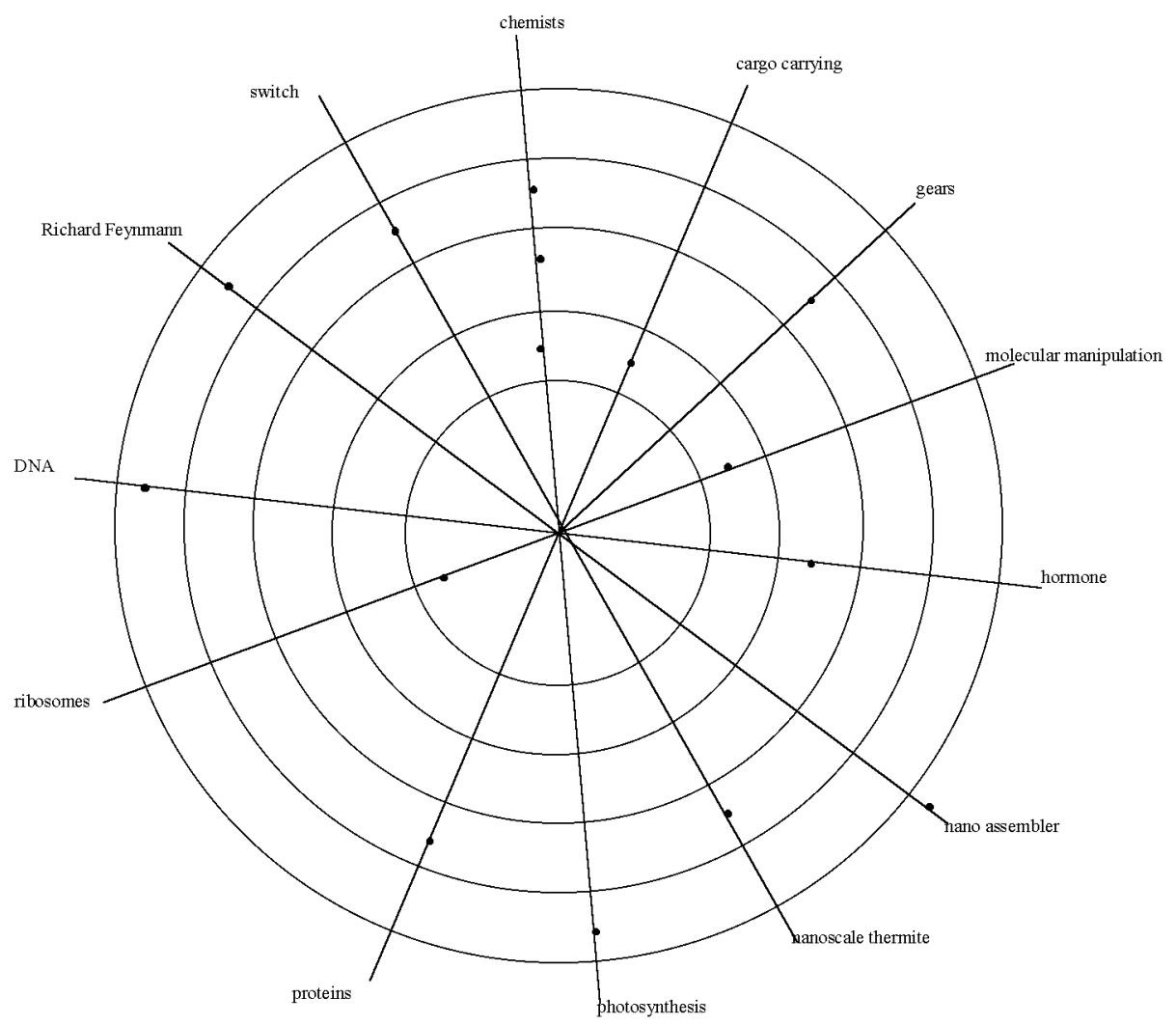

Figure 6c. Modality-maps for (c) molecular machines (New Scientist)

Can we see agglomeration in the ecology of linkages in the field of molecular machines? The three nodes where selected from the dataset due to the large percentage of linkages made to them, but a larger dataset will be necessary. From the research community, physicists (mostly dealing with single molecule mechanics) and biologists (dealing in the main with protein motors) where considerably underrepresented in the data set and thus visions need to be mapped. A similar peer-reviewed journal approach would be useful hear, however, as has been shown, the peer-reviewed journals may not stimulate the articulation of Visionary Linkages or Science Fiction linkages. The New Scientist data showed that here such linkages prevailed. Considering that certain authors made linkages in both data sets (J. Fraser Stoddart and Vincenzo Balzani both leading researchers in molecular machine chemistry) these provide different fora for creating 
linkages. Thus an interesting research question would be to track certain actors and their linkages in different fora.

An important step needs to be taken in exploring the boundaries imposed in different fora for linkage making. An example would be the ETC-group, an NGO active in the nanotechnology debate especially focussed on Grey and Green Goo. Their major forum for making linkages is on websites. The legitimacy and shaping strength of such linkages comes into question, and thus a necessary further step for the tool would be to link fora for linkage making and shaping strength on the field.

An important next step in the exploration should be the visualisation of the authors of the linkage. Perhaps certain linkages come to dominate in a specific field, or perhaps, even more enticing, a community may be identified by those who make similar linkages. For the field of molecular machines this is an interesting entry point and one which the authors will pursue.

\section{Conclusions}

We have demonstrated the tool for a very specific question: what linkages are being made about visions, expectations and agendas in a specific data set (BROWNE \& FERINGA, 2006) and contrasted it with a smaller data set taken from the New Scientist.

The tool allows one to gauge dynamics of an early field where data is heterogeneous and many activities are based on expectations of possible developments. Handling heterogeneity is essential for understanding the dynamics for early stage new and emerging science and technology. In the above, we have outlined a tool to help in measuring the types of linkages made in statements about the emerging field of molecular machines, which could not be obtained easily with other methods. We have investigated the modality to allow us to gauge the (perceived) degree of development of the field. The statement-linkage approach particularly lends itself to rapidly evolving and fluctuating fields, such as those found in nanotechnology.

Its usefulness is in getting a handle on the dynamics of linkages rather than nodes, which presently is a lacunae that needs to be filled within the literature for studies of emerging science and technology fields when the definition of terms and actor communities (nodes) fluctuate. This is certainly the case for nanotechnology, which like the mythical many-headed hydra, sprouts more and more terms and definitions by the time one has conquered a specific term. One can see this at all levels of nanotechnology, from the definition of the umbrella term itself, to sub-fields based on application (Nanomaterials, Nanomedicine etc.), to technology developments (nanpatterned surfaces, functionalised nanoparticles etc.) to scientific disciplines (nanofluidics, bionanotechnology). Thus focussing on linkages perhaps bypasses the problem of taming the many sprouting heads of hydra by accepting the diversity of terms and focussing on the linkage. 
The visualisation approach of the modality map used to present some of the data can be expanded to include changes over time, and networks of linkages. An obvious extension of this approach would be to track linkages in other data sets, such as conferences papers, policy documents, company reports, press releases etc. dependent on which community you wish to explore. This data set could be linked in a dynamic network mapping approach, which could capture the change of types and modality of linkages over time as well as the linkage/node ecology. The full application of the tool to the emerging field of molecular machines would focus on the various communities articulating visions and doing research in the field of molecular machines. This means heterogeneous data set (as outlined above). However, a comparison can be made about the modality of the linkages in each data set, the nodes which are dominant (depending on no. linkages and modality) and the evolution over time. This is in fact part of the extended programme of Molecular Machine mapping, and is work in progress.

Another characteristic, which can be mapped, is the positioning that occurs when and actor makes a linkage in a statement. Following from the work of Harré, van Langenhove and others (HARRÉ et al., 1992; 1999; 2003; VAN LANGENHOVE \& BERTOLINK, 1999) one can see how networks emerge based on how the actor positions himself with respect to the linkage (the author may make a negative or positive linkage thus positioning himself through making this claim). This data may be interesting for unveiling actor strategies in path emergence (GARUD \& KARNØE, 2001; RIP \& RoBINSON, 2006; ROBINSON, 2006a)

By looking at this dynamically one can observe the evolution of terms and emerging stabilities and irreversibilities. Insights into expectation dynamics and emerging irreversibilities coming from such mapping can be integrated into foresight, technology assessment and strategy articulation activities with actors. For a recent example of how this could be done, see RoBINSON \& PROPP (2006) or RoBINSON (2006a).

There are a number of limitations to this approach. The qualitative approach to selecting and coding the statements is dependent on the analyst and thus may not be directly reproducible. The determination of the modalities is also somewhat subjective. This could be lessened by conducting more mapping projects, the further refinement of the coding protocol and improvements on the visualisation techniques will thus be a goal of the authors.

The methodology presented should be considered as the starting point for a much more elaborated statement-linkage mapping toolbox. It shows promise in getting a handle on dynamics of an emerging field at very early stages by enabling a systematic exploration of expectations and visions being articulated by various communities. Broader exploration and testing is needed on a more exhaustive data set and is indeed the intention of the authors. 
D. K. R. RoBINSON et al.: The evolution of new and emerging S\&T

\section{References}

ARThUR, W. B. (1990), Positive feedbacks in the economy, Scientific American, (February) : 80-85.

Balzani, V., Credi, A., Venturi, M. (2003), Molecular Devices and Machines: A Journey into the Nanoworld. Wiley-VCH. 1. Edition.

Borup, M., Brown, N., KonraD, K., VAn Lente, H. (2006), The sociology of expectations in science and technology, Technology Analysis \& Strategic Management, 18 (3/4) : 285-298.

Brown, N., MichaEL, M. (2003), A sociology of expectations: retrospecting prospects and prospecting retrospects, Technology Analysis and Strategic Management, 15 : 3-18.

Browne, W. R., FeringA, B. L. (2006), Making molecular machines work, Nature Nanotechnology, $1: 25-35$.

Callon, M., LaW, J., RIP, A. (1986), Mapping the Dynamics of Science and Technology. London: Macmillan.

Callon, M. (1991), Techno-economic networks and irreversibility, In: J. Law (Ed.) A Sociology of Monsters? Essays on Power, Technology and Domination, London: Routledge, pp. 132-161.

CHо. A. (2001), Small wonder. New Scientist Tech, 7 February 2001, available at www.newscientisttech.com DAVID, P.A. (1985), Clio and the economics of QWERTY, American Economic Review, 75 : 332-337.

Decker, M., Grin, J., Grunwald, A., Mambrey, P., Reuzel, R., Tepper, A., Van Der Wilt, G.J. (2000), Outline. GRIN, J., GRUnwald, A. (Eds) Vision Assessment: Shaping Technology in $21^{\text {st }}$ Century Society. Springer: Heidelberg.

DREXLER K. E. (1986), Engines of Creation: The Coming Era of Nanotechnology. Anchor Books.

FEYNMAN, R. P. (1959), There's Plenty of Room at the Bottom: An Invitation to Enter a New World of Physics. Available online and a published version appears in Caltech's Engineering and Science February 1960 issue: http://www.zyvex.com/nanotech/feynman.html

GARUd, R., KARnøE, P. (2001), Path creation as a process of mindful deviation, In: R. GARUd, P. KARnøE (Eds), Path Dependence and Creation, Mahwah: Lawrence Earlbaum Associates, pp. 1-38.

Grin, J., Grunwald, A. (Eds) (2000), Vision Assessment: Shaping Technology in $21^{\text {st }}$ Century Society. Springer: Heidelberg.

Grunwald, A. (2004), Vision Assessment as a New Element of the FTA Toolbox. EU-Seminar: New Technology Foresight, Forecasting and Assessment Methods, Seville.

Harré, R., Moghaddam, F. (Eds) (2003), The Self and Others: Positioning Individuals and Groups in Personal, Political, and Cultural Contexts. Westport: Praeger.

Harré, R., Van Langenhove, L. (1992), Varieties of positioning, Journal for the Theory of Social Behaviour, 20 : 393-407.

Harré, R., Van Langenhove, L. (Eds) (1999), Positioning Theory: Moral Contexts of Intentional Action. Malden: Blackwell.

HESS, H., BACHAND, G. D. (2005), Biomolecular motors, Nanotoday, 8 : 22-29.

Hess, H., BaChand, G. D., Vogel, V. (2004), Powering nanodevices with biomolecular motors, Chem. Eur. J., $10: 2110-2116$.

Holland, N. B., Hugel, T., Neuert, G., Cattani-Scholz, A., Renner, C., Oesterhelt, D., Moroder, L., Seitz, M., Gaub, H. E. (2003), Single molecule force spectroscopy of azobenzene polymers: switching elasticity of single photochromic macromolecules, Macromolecules, 36 : 2015-2023.

Ismagilov, R. F., Schwartz, A., Bowden, N., Whitesides, G. M. (2002), Autonomous movement and self-assembly, Angewandte Chemie - International Edition, 41 (4) : 652-654.

KinBARA, K., AïDA, T. (2005), Toward Intelligent Molecular Machines: Directed Motions of Biological and Artificial Molecules and Assemblies, Chemical Reviews, 105 : 1377-1400.

Koumara, N., Geerstema, E.M., Van Gelder, M.B., Meetsma, A., Feringa, B.L. (2002), Second generation light-driven molecular motors. Unidirectional rotation controlled by a single stereogenic center with near-perfect photoequilibria and acceleration of the speed of rotation by structural modification, Journal of the American Chemical Society, 124 : 5037-5051.

PARK, R. L. (2003), Tiny terrors, New Scientist Tech, 05 July 2003, available at www.newscientisttech.com 
D. K. R. RoBINSON et al.: The evolution of new and emerging S\&T

RENN, O., Roco, M. C. (2006), Nanotechnology and the need for risk governance, Journal of Nanoparticle Research. April 2006.

RIP, A. (1995), Introduction of new technology: Making use of recent insights from sociology and economics of technology, Technology Analysis \& Strategic Management, 7 (4) : 417-431.

RIP, A., Misa, T., Schot, J. W. (Eds) (1995), Managing Technology in Society. The Approach of Constructive Technology Assessment. London: Pinter Publishers.

RIP, A., Kemp, R. (1998), Technological change, In: S. RAYNer, E. L. Malone (Eds), Human Choice and Climate Change. Columbus: Batelle Press, p. 2.

RIP, A., RoBInSON, D. K. R. (2006), Socio-technical paths as a multi-level phenomenon, exemplified in the domain of nanotechnology. EIASM Workshop on “Organising Paths - Paths of Organising”, Berlin, Germany, 3-4 November 2006.

Robinson, D. K. R. (2006a), The use of the path concept and emerging irreversibilities in the analysis and modulation of nanotechnologies. EIASM Workshop on "Organising Paths - Paths of Organising", Berlin, Germany, 3-4 November 2006.

Robinson, D. K. R. (2006b), Balancing asymmetry in the division of technology assessment labour: Broadening upstream strategy articulation in European nanotechnology research networks through CTA. European Association for the Study of Science and Technology (EASST) Conference. Reviewing Humanness: Bodies, Technologies and Spaces. University of Lausanne, Switzerland 23rd-26th August 2006.

ROBINSON, D. K. R., PROPP T. (2006), Multi-path mapping as strategic intelligence for reflexive alignment in emerging S\&T. Second International Seville Seminar on Future-Oriented Technology Analysis: Impact of FTA Approaches on Policy and Decision-Making, Seville, Spain, 28-29 September 2006.

SchliwA, M., WoEHLKe, G. (2003), Molecular motors, Nature, 422 : 759-765.

SMALlEY, R. (2001), How soon will we see the nanometer-scale robots envisaged by K. Eric Drexler and other molecular nanotechologists? The simple answer is never, Scientific American, 285 (3) : 76-77.

VALlEE, R.B., HoOK, P. (2003), Molecular motors: A magnificent machine, Nature, 421 : 701-702.

van Delden, R. A., Ter Wiel, M. K. J., Pollard, M. M., Vicario, J., Koumara, N., Feringa, B. L. (2005), Unidirectional molecular motor on a gold surface, Nature, 437 : 1337-1340.

VAn Langenhove, L., Bertolink, R. (1999), Positioning and Assessment of Technology. In: R. Harré, L. VAN LANGENHOVE (Eds), Positioning Theory: Moral Contexts of Intentional Action. Malden: Blackwell.

VAn Lente, H. (1993), Promising Technology: The Dynamics of Expectations in Technological Developments. PhD Thesis. Faculteit der wijsbegeerte en maatschappijwetenschappen, Enschede.

VAN LENTE, H., RIP, A. (1998), Expectations in technological developments: an example of prospective structures to be filled in by agency, In: C. DISCO, B. J. R. VAN DER MEUlen (Eds), Getting New Technologies Together, Berlin: Walter de Gruyter, pp. 195-220.

VAN Merkerk, R. O., Robinson, D. K. R. (2006), Characterizing the emergence of a technological field: Expectations, agendas and networks in Lab-on-a-chip technologies, Technology Analysis \& Strategic Management, 18 (3-4). 


\section{Appendix 1}

List of search terms for the New Scientist archive

- Molecular Machine

- Molecular Machines

- Molecular Motor

- Molecular Motors

- Molecular Rotor

- Molecular Rotors

- Molecular Motion

- Nanomachine

- Nanomachines

- Nanomotor
- Nanomotors

- Nanorotor

- Nanorotors

- Nanobot

- Nanobots

- Nano robot

- Nano robots

- Nano assembler

- Grey Goo

\section{Appendix 2}

Technology component or characteristic nodes in the statement-linkage database List of nodes in the statement linkage dataset

- (supra)molecular species

- $\quad 1 \mathrm{C}$ and $1 \mathrm{~T}$ interconversion

- amphidynamic crystals

- $\quad$ antibodies

- apoptosis

- $\quad$ application of photoswitches

- $\quad$ artifical molecular machine

- $\quad$ artifical rotor

- artificial molecular motor

- artificial molecular rotor

- $\quad$ artificial structures

- $\quad$ artificial surface-mounted motor

- assemblers

- $\quad$ assemblies

- ATP synthase

- autonomous

- balance

- Bioelectronics

- biofuel cell

- biological molecular machines

- biomolecular motor

- biological purification

- biological systems

- biology

- biomimicry

- biomotron
- biosensors

- bioweapons attack

- bottom-up construction

- brakes

- Brownian motion

- Brownian motor

- buckyball

- cantenanes

- cargo carrying

- catalytic reactions

- cells

- chemical fuel

- chemical receptor

- chemical synthesis

- chemists

- chirality

- cis-trans isomerization

- cogwheels

- combination

- commercial product

- communication

- complex tasks

- computation

- computational scientists

- controllable molecular motion

- controlled chemical reactions 
- $\quad$ crystalline molecular machines

- crystals

- cyclodextrin

- $\quad$ cytoskeletal motor

- device

- DNA

- DNA device

- drug delivery

- electrical energy

- electrodes

- electromagnetic radiation

- $\quad$ electron transfer processes

- $\quad$ electronic and nuclear rearrangements

- $\quad$ endergonic chemical reactions energy conversion

- engineering

- engineers

- enzymers

- $\quad$ Eric Drexler

- experimental system

- factories on a chip

- family of compounds

- fears

- feringa motor

- fluctuation driven transport

- $\quad$ fluidic gears

- friction

- fuelled molecular motions

- functional molecules

- future applications

- gears

- global ecophagy

- Grey goo

- helicases

- hormone

- human enhancement

- human implant

- $\quad$ hybrid molecular machines

- immortality

- immune systems

- $\quad$ inorganic materials

- input

- integration

- intramolecular mechanism

- junction

- Kinesin

- Lieber

- life

- lifts

- light powered

- linear motor

- living cells

- logic operations

- machines
- macroscopic analogues

- macroscopic change

- major endeavors

- mall metal complex

- material scientists

- materials at the bulk leve

- mechanical actuator

- mechanical devices

- mechanical systems

- mechanical-like movements

- mechanically linked rotor

- medicine

- memory chips

- metallacarboranes

- microfluidics

- micromachnes

- microrobots

- microrotors

- microscopic wind farm

- miniature "engines"

- miniature electronic circuits

- miniaturisation

- molecular assembler

- molecular assemblies

- molecular bonding

- molecular components

- molecular design

- molecular electronics

- molecular elevator

- molecular gear

- molecular gyroscopes

- molecular machines

- molecular manipulation

- molecular memory

- molecular microchips

- molecular models

- molecular motions

- molecular motor array

- molecular motors

- molecular muscles

- molecular piston

- molecular pumps

- molecular ratchet

- molecular rotors

- molecular scissors

- molecular shuttles

- molecular sorters

- molecular structure

- molecular switches

- molecular-scale

- molecules

- Montemagno

- Moore

- motion coupling 
D. K. R. RoBinson et al.: The evolution of new and emerging S\&T

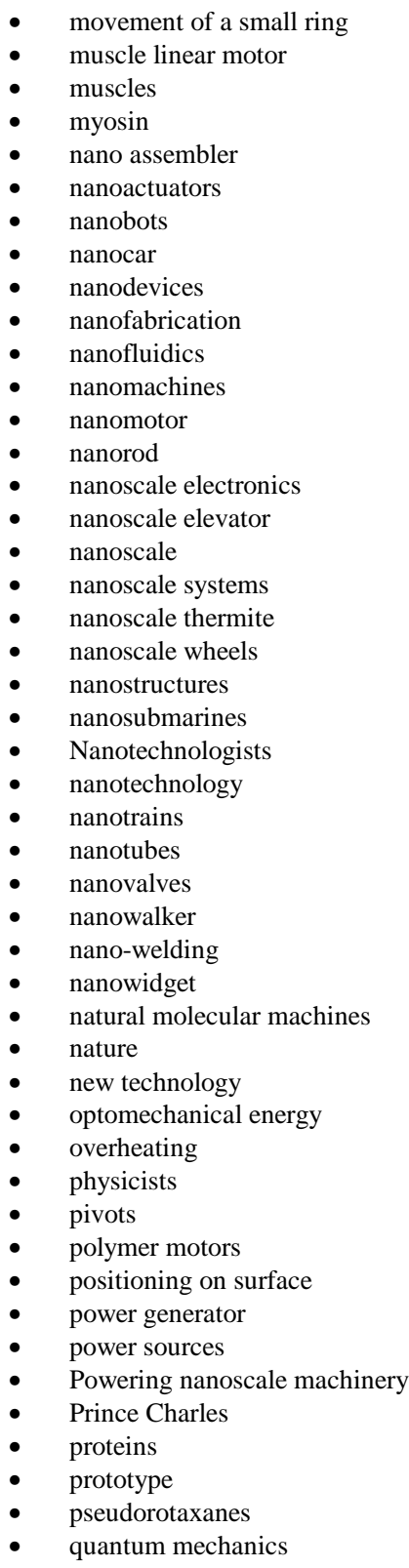

- ratchets

- real issues

- retrieval systems

- reversible helicity

- revolution

- ribosomes

- Richard Feynman

- rotational motion

- rotors

- $\quad$ self assembly

- $\quad$ self-healing materials

- $\quad$ self-replicating nanomachines

- sensors

- $\quad$ shafts

- shuttles

- $\quad$ similar propulsion mechanism

- $\quad$ simple electron transfer processes

- $\quad$ single molecule device

- $\quad$ single-molecular machine

- $\quad$ small machines

- Smalley

- smart surfaces

- $\quad$ society

- $\quad$ speed of rotation

- $\quad$ statistical theories

- steam engine

- $\quad$ stereogenic center

- $\quad$ studying toxic surfaces

- submarines

- submolecular fragment

- submolecular motion

- supramolecular organization in materials

- $\quad$ surface of gold nanoparticles

- switch

- $\quad$ synthetic oxygen

- $\quad$ system

- top-down fabrication

- trans-cis isomerizations

- transport

- tweezers

- unidirectional rotary motion

- universal fabricator

- useful work

- valve

- variety of environments (environments)

- $\quad$ viruses 